\title{
Effects of Caffeine on Topographic Quantitative EEG
}

\author{
Martin Siepmann Wilhelm Kirch \\ Institute of Clinical Pharmacology, Medical Faculty, Technical University, Dresden, Germany
}

\section{Key Words}

Topographical quantitative EEG · Caffeine .

Psychostimulants effects of psychostimulants on the human brain. Therefore, in pharmaco-EEG studies, environmental factors such as caffeine have to be excluded.

Copyright $@ 2002$ S. Karger AG, Basel

\begin{abstract}
Despite the widespread use of caffeine as a central nervous stimulant, the central pharmacodynamic properties of the drug have not yet been conclusively evaluated in humans. The present study was undertaken to assess the acute effects of caffeine on measures of topographical quantitative electroencephalogram (EEG) in normal subjects. Ten healthy male volunteers (mean age \pm SD $25 \pm$ 4 years) received placebo and $200 \mathrm{mg}$ of caffeine as powder with oral water solution (caffeine amount $=2$ cups of coffee) under randomized, double-blind crossover conditions on two different occasions. Before administration and $30 \mathrm{~min}$ afterwards, a 17-channel quantitative EEG was recorded during relaxation with eyes open and closed (15 min each). Caffeine caused a significant reduction of total EEG power at fronto-parieto-occipital and central electrode positions of both hemispheres when the subjects kept their eyes open. Absolute power of the slow and fast alpha and slow beta activities was diminished in various regions of the brain $(p<0.05)$. The effect was more pronounced with the subjects keeping their eyes open than with eyes closed. It can be concluded that quantitative EEG is a sensitive method to assess the
\end{abstract}

\section{Introduction}

Caffeine (1,3,7-trimethylxanthine), a component of tea, coffee and soft drinks, is the most widely used psychoactive agent in the world [1]. Studies in North America show a daily intake of approximately $200 \mathrm{mg}$ per adult [2]. The acute administration of this dose increases alertness, stimulates attention and restores performance degraded by factors such as fatigue and boredom [3]. However, a wide variation in the behavioral effects of caffeine has been demonstrated in humans receiving doses of this magnitude [4]. The changes in brain state brought about by caffeine are generally described in terms of increases in excitatory processes, reduced inhibitory processes and/or increased availability of energy. The global picture of excitatory effects has correlates at the global-physiologic level manifest in the spontaneous background electroencephalogram (EEG). Topographical quantitative EEG measures provide a neurophysiological assessment of brain activity that correlates with behavior [5]. EEG power spectrum variables have been used for classification of psychotropic drugs such as stimulants, antidepressants

\begin{tabular}{ll}
\hline KARGER & ( ) 2002 S. Karger AG, Basel \\
Fax +41613061234 & $0302-282 X / 02 / 0453-0161 \$ 18.50 / 0$ \\
$\begin{array}{l}\text { E-Mail karger@karger.ch } \\
\text { www.karger.com }\end{array}$ & $\begin{array}{l}\text { Accessible online at: } \\
\text { www.karger.com/journals/nps }\end{array}$
\end{tabular}

M. Siepmann, MD
Institute of Clinical Pharmacology, Medical Faculty, Technical University
Fiedlerstrasse 27, D-01307 Dresden (Germany)
Tel. +49 351 4585694, Fax +49 3514584341
E-Mail Martin.Siepmann@mailbox.tu-dresden.de 
Table 1. Total EEG power $(1.25-35.00 \mathrm{~Hz})$

\begin{tabular}{|c|c|c|c|c|c|c|c|c|}
\hline \multirow[t]{2}{*}{ Electrode } & \multicolumn{4}{|c|}{ EEG power with eyes open, $\mathrm{Hz}$} & \multicolumn{4}{|c|}{ EEG power with eyes closed, $\mathrm{Hz}$} \\
\hline & baseline & caffeine & baseline & placebo & baseline & caffeine & baseline & placebo \\
\hline $\mathrm{F}_{\mathrm{z}}$ & $28.9(43.8)$ & $26.3(38.6)^{*}$ & $26.6(47.9)$ & $30.8(53.3)$ & $33.5(75.4)$ & $29.5(72.7)$ & $36.2(85.5)$ & $42.7(75.6)$ \\
\hline $\mathrm{F}_{3}$ & $27.5(54.6)$ & $25.9(51.4)^{*}$ & $24.4(53.6)$ & $27.8(50.6)$ & $30.8(74.9)$ & $27.5(70.6)$ & $34.9(82.1)$ & $38.6(67.9)$ \\
\hline $\mathrm{F}_{4}$ & $25.8(78.1)$ & $22.0(32.3)^{*}$ & $24.5(62.5)$ & $27.1(54.8)$ & $33.1(81.1)$ & $29.3(83.2)$ & $35.4(75.5)$ & $41.7(82.7)$ \\
\hline $\mathrm{F}_{7}$ & $40.1(57.8)$ & $39.1(79.5)$ & $38.6(87.6)$ & $42.4(90.0)$ & $38.1(69.9)$ & $37.5(65.9)$ & $37.5(66.2)$ & $40.1(63.9)$ \\
\hline $\mathrm{F}_{8}$ & $36.3(187.8)$ & $33.4(99.4)$ & $37.2(91.8)$ & $38.2(106.2)$ & $38.0(67.8)$ & $40.4(73.1)$ & $40.0(55.5)$ & $42.5(68.6)$ \\
\hline $\mathrm{C}_{\mathrm{z}}$ & $14.7(30.2)$ & $12.5(24.0)^{*}$ & $11.8(36.3)$ & $12.5(28.6)$ & $19.5(64.0)$ & $17.1(50.1)$ & $20.4(45.5)$ & $23.7(50.1)$ \\
\hline $\mathrm{C}_{3}$ & $16.9(24.1)$ & $12.9(21.1)^{*}$ & $15.1(26.5)$ & $16.2(24.8)$ & $20.8(45.4)$ & $17.2(45.6)$ & $20.3(46.8)$ & $23.8(42.1)$ \\
\hline $\mathrm{C}_{4}$ & $16.7(26.1)$ & $13.0(18.8)^{*}$ & $13.8(20.9)$ & $17.5(21.9)$ & $20.7(34.6)$ & $17.7(37.6)$ & $23.9(29.9)$ & $24.3(33.8)$ \\
\hline $\mathrm{T}_{3}$ & $22.7(41.4)$ & $20.0(27.1)$ & $22.2(59.8)$ & $23.5(38.8)$ & $22.0(50.8)$ & $21.0(35.5)$ & $25.2(60.9)$ & $25.7(55.0)$ \\
\hline $\mathrm{T}_{4}$ & $21.9(31.4)$ & $22.5(38.2)$ & $20.0(34.0)$ & $21.4(33.5)$ & $24.3(55.3)$ & $22.1(52.9)$ & $26.4(41.7)$ & $26.7(54.4)$ \\
\hline $\mathrm{T}_{5}$ & $20.8(35.9)$ & $17.1(29.7)$ & $23.7(38.1)$ & $22.3(34.8)$ & $40.2(63.1)$ & $30.4(82.8)$ & $40.3(91.7)$ & $49.2(93.1)$ \\
\hline $\mathrm{T}_{6}$ & $25.2(51.8)$ & $21.1(41.3)^{*}$ & $21.5(56.6)$ & $21.7(46.3)$ & $48.0(178.0)$ & $57.9(151.2)$ & $53.5(146.2)$ & $54.3(157.7)$ \\
\hline $\mathrm{P}_{\mathrm{z}}$ & $22.0(69.2)$ & $18.1(29.1)$ & $20.8(33.6)$ & $21.6(45.0)$ & $35.8(140.9)$ & $29.2(133.0)$ & $31.5(109.1)$ & $34.9(141.0)$ \\
\hline $\mathrm{P}_{3}$ & $20.8(31.3)$ & $16.5(25.9)^{*}$ & $23.3(35.3)$ & $20.6(32.9)$ & $36.4(68.4)$ & $24.1(69.2)$ & $32.9(62.7)$ & $41.9(75.2)$ \\
\hline $\mathrm{P}_{4}$ & $20.9(65.7)$ & $17.0(26.0)^{*}$ & $18.9(27.4)$ & $20.8(32.1)$ & $37.8(145.1)$ & $36.7(132.6)$ & $34.4(94.5)$ & $35.6(105.4)$ \\
\hline $\mathrm{O}_{1}$ & $29.9(28.1)$ & $22.6(30.7)^{*}$ & $30.4(42.7)$ & $32.4(54.0)$ & $55.6(97.2)$ & $74.0(112.1)$ & $74.6(153.8)$ & $58.1(155.5)$ \\
\hline $\mathrm{O}_{2}$ & $30.3(36.9)$ & $24.1(35.9)^{*}$ & $34.4(54.7)$ & $32.6(44.0)$ & $70.3(76.5)$ & $64.7(122.5)$ & $88.0(140.7)$ & $83.8(107.3)$ \\
\hline
\end{tabular}

Results are shown as median and range in parentheses. ${ }^{*} \mathrm{p}<0.05$ versus baseline and placebo.

and tranquilizers [6]. However, previous studies on the effect of caffeine on EEG are inconsistent regarding the direction of the effect of caffeine on EEG power. Kenemans and Lorist [7] as well as Dimpfel et al. [8] found reductions in power, whereas Hasenfratz and Bättig [9] and Etevenon et al. [10] found increases. Difficulties in comparing the power shifts across studies are due to the circumstance that some experiments compare baseline effects with a single dose while others compare changes across a range of caffeine doses. The present study was undertaken to rigorously examine the effects of $200 \mathrm{mg}$ of caffeine given as a single dose to healthy subjects on the CNS-relevant variables of topographical quantitative EEG.

\section{Subjects and Methods}

\section{Subjects}

Ten healthy male subjects aged 22-33 years (mean \pm SD $25 \pm 4$ years), weighing between 59 and $84 \mathrm{~kg}(71 \pm 8 \mathrm{~kg})$ and $171-184 \mathrm{~cm}$ $(179 \pm 5 \mathrm{~cm})$ in height were enrolled in the study. The study was conducted according to the Declaration of Helsinki (Sommerset West Amendment 1996). Written informed consent from the subjects and approval from the Hospital Ethics Committee (Dresden,
Germany) were obtained. The subjects were moderate users of caffeine. This means they consumed 1-2 cups of coffee per day. They were included after a standard physical examination, clinical laboratory tests and a 12-lead ECG.

\section{Protocol}

The subjects were not allowed to smoke or to consume alcoholic or caffeine-containing beverages for $10 \mathrm{~h}$ before and during the trial. They had to have been free of medication for at least 14 days. After an overnight fast, the subjects presented themselves in the morning. They received $200 \mathrm{mg}$ of caffeine orally as powder with $150 \mathrm{ml}$ of water solution as well as placebo (glucose) on two different occasions under randomized, double-blind, crossover conditions. All recordings took place in a quiet room with the subjects sitting in a comfortable chair.

Quantitative EEG was recorded before and 30 min after ingestion of caffeine and placebo with the subjects keeping their eyes open and closed for periods of 15 min each. Heart rate was monitored by hand at the end of each period.

\section{Topographical Quantitative EEG}

Data acquisition and signal analysis followed the guidelines of the International Pharmaco-EEG Group [11]. Details of the methods have been described elsewhere [12]. Briefly, the EEG was recorded bipolarly from 17 surface electrodes by means of an electrode cap according to the standard 10-20 system with $\mathrm{C}_{\mathrm{z}}$ as physical reference. EEG signals were amplified with a Cateem ${ }^{\circledR}$ apparatus (Proscience, Linden, Germany) and sampled at a rate of $512 \mathrm{~Hz}$ and 12 bit. ECG and electrooculogram were recorded simultaneously. Arti-

\footnotetext{
$162 \quad$ Neuropsychobiology 2002;45:161-166
} 
facts were rejected automatically. Analog signals were displayed on a separate monitor for visual control. The signals of all EEG electrodes were frequency analyzed with the fast Fourier transformation, based on sweeps of 4-second data epochs by means of a Hanning window. In the resulting spectrum, six frequency bands were defined: delta $(1.25-4.50 \mathrm{~Hz})$, theta $(4.75-6.75 \mathrm{~Hz})$, alpha $1(7.00-9.50 \mathrm{~Hz})$, alpha $(9.75-12.50 \mathrm{~Hz})$, beta $_{1}(12.75-18.50 \mathrm{~Hz})$ and beta $_{2}(18.75-35.00$ $\mathrm{Hz})$. Absolute power values $\left(\mu \mathrm{V}^{2}\right)$ were calculated for the frequency bands and the entire spectrum $(1.25-35.00 \mathrm{~Hz})$.

\section{Statistical Analysis}

All data were analyzed using the Sigma Stat software package (Jandel, San Rafael, Calif., USA). Evaluation was done with a oneway ANOVA procedure for repeated measurements. Friedman repeated-measures ANOVA on ranks was performed when values were not normally distributed. If significant, Student-Newman-Keuls post hoc tests were used for comparisons between treatment conditions. Statistical significance was accepted at $\mathrm{p}<0.05$.

\section{Results}

After administration of caffeine, total power in the quantitatively analyzed EEG was significantly reduced at frontal $\left(\mathrm{F}_{\mathrm{z}}, \mathrm{F}_{3}, \mathrm{~F}_{4}\right)$, central $\left(\mathrm{C}_{\mathrm{z}}, \mathrm{C}_{3}, \mathrm{C}_{4}\right)$, temporal $\left(\mathrm{T}_{6}\right)$, parietal $\left(\mathrm{P}_{3}, \mathrm{P}_{4}\right)$ and occipital $\left(\mathrm{O}_{1}, \mathrm{O}_{2}\right)$ electrode positions when the subjects kept their eyes open $(p<0.05$; table 1$)$. A trend in the same direction was seen with eyes closed in frontal $\left(\mathrm{F}_{\mathrm{z}}, \mathrm{F}_{3}, \mathrm{~F}_{4}, \mathrm{~F}_{7}\right)$, central $\left(\mathrm{C}_{\mathrm{z}}, \mathrm{C}_{3}, \mathrm{C}_{4}\right)$, temporal $\left(\mathrm{T}_{3}\right.$, $\left.\mathrm{T}_{4}, \mathrm{~T}_{6}\right)$, parietal $\left(\mathrm{P}_{3}, \mathrm{P}_{4}, \mathrm{P}_{\mathrm{z}}\right)$ and occipital leads $\left(\mathrm{O}_{2}\right)$, although statistical significance was not reached $(\mathrm{p}>$ 0.05). As shown in figures 1 and 2, caffeine significantly reduced absolute power in the slow and fast alpha $\left(\right.$ alpha $_{1}$ and alpha $\left._{2}\right)$ as well as the slow beta $\left(\right.$ beta $\left._{1}\right)$ frequency ranges at various electrode positions under the eyes open condition. Alpha power was not significantly affected,

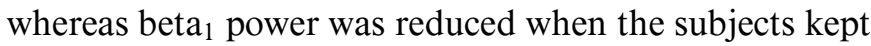
their eyes closed. Theta and delta activities were diminished in a few leads under both conditions. No concomitant changes in heart rate were noted. No specific topographical distribution of the EEG changes was noted. However, the reduction of alpha power was accentuated in frontal and occipital regions of both hemispheres (fig. 1, 2).

\section{Discussion}

This study confirms the findings of a number of recent studies that caffeine attenuates total power $(1.5-35 \mathrm{~Hz})$ in the quantitatively analyzed EEG [7, 8, 13, 14]. The effect was observed at frontal, parietal, occipital and central electrode positions. All frequency ranges were concerned,

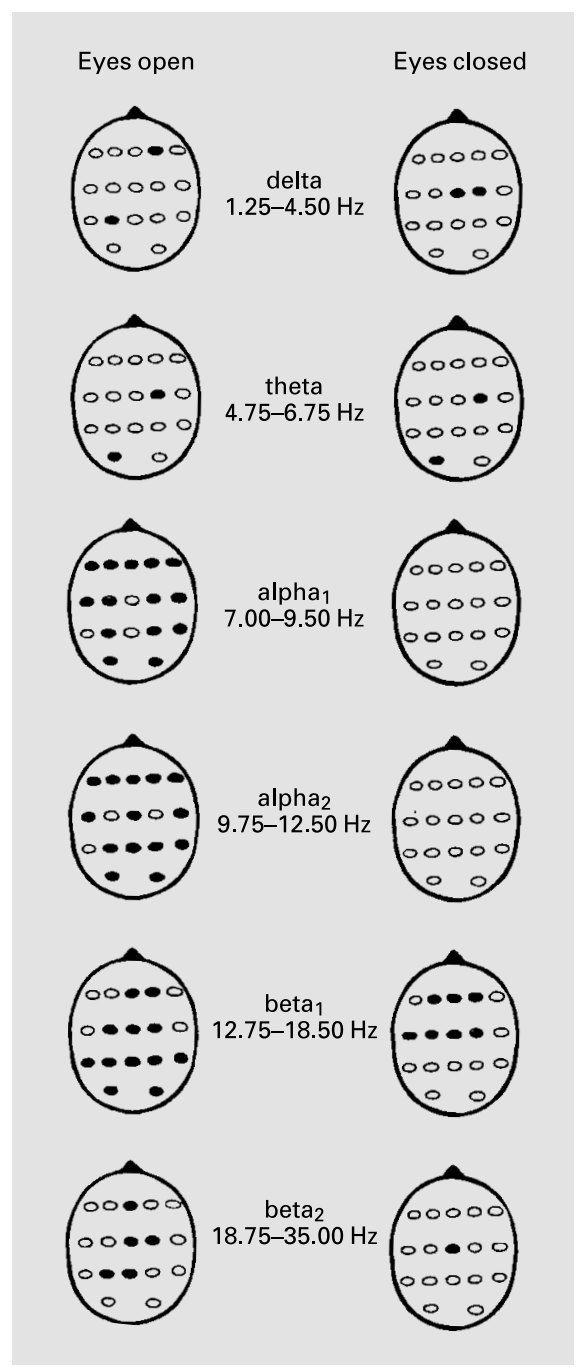

Fig. 1. Spectral power changes following oral administration of $200 \mathrm{mg}$ of caffeine. Filled circles show a decrease $(\mathrm{p}<0.05)$ and open circles no significant change $(\mathrm{p}>0.05)$ as compared with baseline and placebo. 


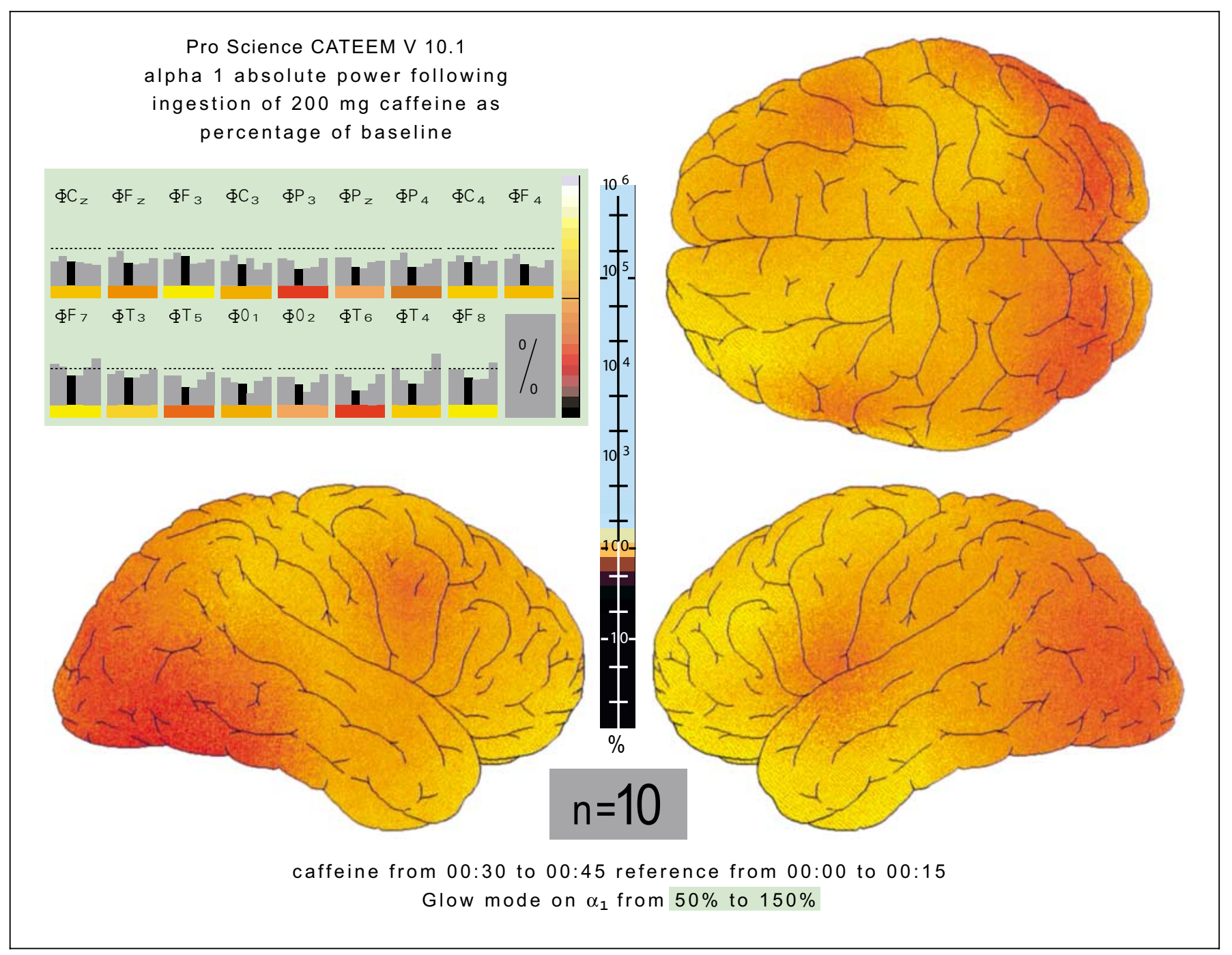

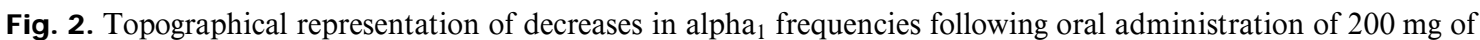
caffeine under the eyes open condition. Documentation of all values was made according to the 'glow mode' (50$150 \%)$ in the percentage of baseline. Caffeine-induced decreases of absolute power appear darker.

of minimal or no effects $[17,18]$ or power-increasing effects of caffeine $[9,10]$ seem to be due to differences in baseline, dose and even recording conditions, e.g. resting EEG versus vigilance-controlled EEG. Although not the focus of the present study, other studies have shown that withdrawal from caffeine results in an increase in EEG power which can be reversed by administration of caffeine $[19,20]$.

The primary mechanism of action of caffeine is adenosine receptor antagonism, by blocking cAMP formation [21]. Since adenosine, a neuromodulator released during normal cortical metabolic activity, acts to depress synaptic activity and inhibit neurotransmitter release, con- sumption of caffeine acts as a powerful moderator of this function. In addition, caffeine ingestion has also been associated with increases in the rate of catecholamine synthesis [15], which is significant with respect to the stimulant properties of caffeine, because of the role that the reticular system plays in the modulation of cortical arousal. The stimulant effects of caffeine are associated with changes in the local rates of cerebral energy metabolism.

Experiments in rats show that acute doses of caffeine of $10 \mathrm{mg} / \mathrm{kg}$ increase cerebral glucose utilization in monoaminergic cell groupings like the substantia nigra and ventral tegmental area, which are rich in dopamine, medial and dorsal raphe nuclei, which contain serotonin, and the 
locus ceruleus, which is rich in noradrenaline [22]. Caffeine increases the rates of energy metabolism in the structures of the extrapyramidal motor system and in numerous thalamic nuclei and limbic areas such as the hippocampus [23]. These local increases of cerebral glucose utilization which are involved in the sleep/wake cycle correlate with behavioral modifications as mentioned above [15]. Caffeine induces a decrease in local cerebral blood flow, mainly in the areas where it increases metabolism, i.e. in monoaminergic cell groupings, in the limbic system and in the thalamus [24]. Contrary to the majority of pharmacological agents to which humans are frequently exposed, caffeine has the property of inducing cerebral hypoperfusion accompanied by a simultaneous increase in glucose utilization. Like other methylxanthines, e.g. theophylline, caffeine thus seems to modify the regulating mechanism between blood flow and cerebral metabolism in the CNS. Although this mechanism is not yet well understood, adenosine, with which methylxanthines compete, is known to be one of the modulators of the regulation of the relationship of blood flow to metabolism in the central nervous system [25]. It is highly speculative to extend conclusions from experiments in animals such as rats to humans. Parameters of quantitative EEG can be employed to monitor drug effects on cerebral blood flow and metabolism in humans [26]. Vasodilating agents such as glyceroltrinitrate increase EEG power, whereas vaso- constricting agents such as indomethacin decrease EEG power in healthy subjects $[27,28]$. In the present study, $200 \mathrm{mg}$ of caffeine, which is comparable to the caffeine amount in 2 cups of coffee, caused a significant attenuation of EEG power in various brain regions. It has been shown that cerebral metabolism and EEG power are inversely related in normal subjects [29]. Caffeine acts as a vasoconstrictor. It subsequently decreases cerebral voltage. Usage of caffeine may affect cerebral functioning more profoundly than has previously been suspected. While quantitative EEG is being increasingly used to study neurophysiologic effects of various substances, caffeine usage is not currently considered or controlled in such investigations. Our findings suggest that usage of relatively small amounts of caffeine may have a significant effect on cerebral voltage. Of particular importance would be studying chronic caffeine use and evaluation of frequency changes.

In conclusion, single doses of $200 \mathrm{mg}$ of caffeine attenuate EEG power at various electrode positions. The effect is most pronounced in the alpha bands.

\section{Acknowledgements}

The authors are sincerely thankful to H. Völkel, M. Schneider and U. Ebert for their technical assistance in conducting the study.

\section{References}

1 Gilbert RM: Caffeine consumption; in Spiller GA (ed): The Methylxanthine Beverages and Foods: Chemistry, Consumption, and Health Effects. New York, Liss, 1984, pp 185-213.

2 Wells SJ: Caffeine: Implications of recent research for clinical practice. Am J Orthopsychiatry 1984;54:375-389.

3 Weiss B, Laties V: Enhancement of human performance by caffeine and the amphetamines. Pharmacol Rev 1962;14:1-36.

4 Israel Y (ed): Research Advances in Alcohol and Drug Problems. New York, Kluwer Academic, 1982.

5 Itil TM: Dynamic brain mapping methodology and application. Int J Psychophysiol 1991;10: 281-291.

6 Herrmann WM, Fichte K, Itil TM, Kubicki S: Development of a classification rule for four clinical therapeutic psychotropic drug classes with EEG power-spectrum variables of human volunteers. Pharmakopsychiatr Neuropsychopharmakol 1979;12:20-34.

7 Kenemans JL, Lorist M: Caffeine and selective visual processing. Pharmacol Biochem Behav 1995;52:461-471
8 Dimpfel W, Schober F, Spuler M: The influence of caffeine on human EEG under resting conditions and during mental loads. J Clin Invest 1993;71:197-207.

9 Hasenfratz M, Bättig K: Acute dose-effect relationships of caffeine and mental performance, EEG, cardiovascular and subjective parameters. Psychopharmacology (Berl) 1994;114: 281-287.

10 Etevenon P, Peron-Magnan P, Boulenger JP, Tortrat D, Guillou S, Toussaint M, Gueguen B, Deniker P, Zarifian E: EEG cartography profile of caffeine in normals. Clin Neuropharmacol 1986;9(suppl 4):538-540.

11 Dumermuth G, Ferber G, Herrmann WM, Hinrichs H, Künkel H: International Pharmaco-EEG Group (IPEG). Committee on standardization of data acquisition and analysis in pharmaco-EEG investigations. Neuropsychobiology 1987;17:213-218.

12 Ebert U, Siepmann M, Oertel R, Wesnes KA, Kirch W: Pharmacokinetics and pharmacodynamics of scopolamine after subcutaneous administration. J Clin Pharmacol 1998;38:720726.
13 Goldstein L, Murphree HB, Pfeiffer CC: Quantitative electroencephalography in man as a measure of CNS stimulation. Ann NY Acad Sci 1963;107:1045-1056.

14 Saletu B, Anderer P, Kinsperger K, Grünberger $\mathrm{J}$ : Topographic brain mapping of EEG in neuropsychopharmacology. II. Clinical applications (pharmaco EEG imaging). Methods Find Exp Clin Pharmacol 1987;9:385-408.

15 Nehlig A, Daval JL, Debry G: Caffeine and the central nervous system: Mechanisms of action, biochemical, metabolic, and psychostimulant effects. Brain Res Brain Res Rev 1992;17:139_ 169.

16 Saletu B, Barbanoj MJ, Anderer P, Sieghart W, Grünberger J: Clinical-pharmacological study with the two isomers (d-, 1-) of fenfluramine and its comparison with chlorpromazine and damphetamine: Blood levels, EEG mapping and safety evaluation. Methods Find Exp Clin Pharmacol 1993;15:291-312.

17 Pritchard WS, Robinson JH, DeBethizy JD, Davis RA, Stiles MF: Caffeine and smoking: Subjective, performance and psychophysiological effects. Psychophysiology 1995;32:19-27. 
18 Pollock VE, Teasdale T, Stern J, Volavka J: Effects of caffeine on resting EEG and response to sine wave modulated light. Electroencephalogr Clin Neurophysiol 1981;51:470-476.

19 Reeves RR, Struve FA, Patrick G, Bullen JA: Topographic quantitative EEG measures of alpha and theta power changes during caffeine withdrawal: Preliminary findings from normal subjects. Clin Electroencephalogr 1995;26: 154-162.

20 Jones HE, Herning RI, Cadet JL, Griffiths RR Caffeine withdrawal increases cerebral blood flow velocity and alters quantitative electroencephalography (EEG) activity. Psychopharmacology (Berl) 2000;147:371-377.

21 Daly JW, Bruns RF, Snyder SH: Adenosine receptors in the central nervous system: Relationship to the central actions of methylxanthines. Life Sci 1981;28:2083-2097.
22 Nehlig A, Lucignani G, Kadekaro M, Porrino LJ, Sokoloff L: Effects of acute administration of caffeine on local cerebral glucose utilization in the rat. Eur J Pharmacol 1984;101:91-100.

23 Grome JJ, Stefanovich V: Differential effects of methylxanthines on local cerebral blood flow and glucose utilization in the conscious rat. Naunyn Schmiedebergs Arch Pharmacol 1986; 333:172-177.

24 Nehlig A, Pereira De Vasconcelos A, Dumont I, Boyet S: Effects of caffeine, L-phenylisopropyladenosine and their combination on local cerebral blood flow in the rat. Eur J Pharmacol 1990;179:271-280.

25 Berne RM, Winn RH, Rubio R: The local regulation of cerebral blood flow. Prog Cerebrovasc Dis 1981;24:243-260.
26 Leuchter AF, Uijtdehaage SH, Cook IA, O'Hara R, Mandelkern M: Relationship between brain electrical activity and cortical perfusion in normal subjects. Psychiatry Res 1999; 90:125-140.

27 Siepmann M, Kirch W: Effects of nitroglycerine on cerebral blood flow velocity, quantitative electroencephalogram and cognitive performance. Eur J Clin Invest 2000;30:832-837.

28 Kraaier V, Van Huffelen AC, Wieneke GH, Van der Worp HB, Bar PR: Quantitative EEG changes due to cerebral vasoconstriction. Indomethacin versus hyperventilation-induced reduction in cerebral blood flow in normal subjects. Electroencephalogr Clin Neurophysiol 1992;82:208-212.

29 Buchsbaum MS, Kessler R, King A, Johnson J, Cappelletti J: Simultaneous cerebral glucography with positron emission tomography and topographic electroencephalography. Prog Brain Res 1984;62:263-269. 